\title{
Experimental investigation on performance of a turbocharged DI diesel engine using isopropanol-diesel fuel blends
}

\author{
Bin Xu, Yibin Liu ${ }^{\mathrm{a}}$, Jianhao Jia, Jian Wu, Weiwei Shang and Zhihao Ma \\ College of Vehicle and Transportation Engineering, Henan University of Science and Technology, China
}

\begin{abstract}
Experimental study was conducted to investigate the effects of using isopropanoldiesel fuel blends on the engine performance and exhaust emissions in an electronic control high-pressure common rail turbocharged direct injection diesel engine. Experiments have been performed for different isopropanol-diesel blends, kept at different blending proportions, P5 (P5 contains 5\% isopropanol and 95\% diesel fuel by v/v), P10, P15 and P20, at engine speed of 2000r/min and different loads. The performance, combustion and emission characteristics observed while using blended fuels were analysed and compared with that of pure diesel as fuel without adding isopropanol. The results show that the isopropanol addition can significantly improve smoke emissions. The THC and NOx emissions increased except CO emissions. Isopropanol-diesel fuel blends provide little effect on the in-cylinder pressure and heat release rate at selected operating conditions. Brake specific fuel consumption of isopropanol-diesel fuel blends becomes higher than diesel fuel.
\end{abstract}

Keywords: diesel engines; isopropanol; combustion; emissions; performance.

\section{Introduction}

Diesel engines are the most common internal combustion engines that are widely used in various sectors such as agriculture, transportation and industry, due to their excellent drivability and fuel economy. They are expected to become more widespread in the foreseeable future. The increasing concern about the energy demand, depleting oil reserves and the instability of the prices of fossil fuels, together with environmental and health problems related to atmospheric pollution, are impelling the search of alternative cleaner fuels that can alleviate such problems.

Alternative fuels in general can be divided them into three categories:

-Oxygenated fuels such as alcohol, ether, ester (mainly including methanol, ethanol, dimethyl ether, micro algae oil as well as the production of biodiesel from vegetable oil);

-Synthetic oil, (produced by coal, natural gas or biomass liquid fuel, such as waste plastics oil);

-Gas fuel (natural gas, liquefied petroleum gas, hydrogen gas, coal gas, methane, etc.). [1-6]

The advantages of alcohols as a fuel include:

-Lower viscosity compared to diesel fuel, therefore it better performance of atomization and evaporation, then it can be mixed with air easily;

-Due to its higher stoichiometric fuel-air ratio, oxygen content, $\mathrm{H} / \mathrm{C}$ ratio and lower sulfur content, therefore its emission is less;

\footnotetext{
a Corresponding author : lyb_900909@126.com
} 
- High engine volumetric efficiency because of its higher evaporative cooling, which results in a cooler intake process and compression stroke;

-Shorter combustion duration due to its high laminar flame propagation speed, which may improve the engine thermal efficiency. [7-10]

Recently, propanol and butanol isomers are increasing their attractiveness as fuels that may be produced from renewable sources. [11]

A few research has been carried out on the isopropanol as an alternative fuel. Lv Xingcai etc. [12] used neat n-heptane, and 10\% 60\% (by volume) isopropanol/n- heptane blend fuels on a single cylinder HCCI engine at $1800 \mathrm{r} / \mathrm{min}$. The experimental results reveal that the ignition timing of low temperature reaction (LTR) retards, and the peak values of heat release during the LTR decreases with the increase of isopropanol in blend fuels. Holtzapple, M.T. etc. [13] found that through the MixAlco Process converts biomass into mixed alcohol fuels. The biomass is first treated with lime to render it more digestible. Then, it is fed to a mixed culture of acid-forming microorganisms that produce salts of volatile fatty acids. These salts are separated from the fermentation broth and thermally converted to ketones that are subsequently hydrogenated to alcohols, such as 2-propanol, 2-butanol, 2-pentanol, and 3-pentanol. Myburgh, I.S. [14] investigated a fuel blend containing 20\% so-called "propanolplus" and $80 \%$ SASOL diesel was tested in a 4-cylinder direct-injection diesel engine. Performance results with standard injection pump settings indicated that in comparison with operation on pure diesel, operation on the propanol-plus/diesel blend reduced the power by roughly $5 \%$ throughout the speed range. In addition, the volumetric fuel consumption was increased by, on average, 5.5\% throughout the speed and load ranges.

Table 1. The principal parameters of diesel engine.

\begin{tabular}{|c|c|}
\hline Description & Specification \\
\hline Engine model & GW4D20 \\
\hline Cylinder & 4 \\
\hline Bore\& Stroke & $83.1 \mathrm{~mm} \& 92 \mathrm{~mm}$ \\
\hline Displacement & $1.996 \mathrm{~L}$ \\
\hline Compression ratio & $16.7: 1$ \\
\hline Rated output \& speed & $110 \mathrm{~kW} \& 4000 \mathrm{r} / \mathrm{min}$ \\
\hline Maximum torque \& speed & $310 \mathrm{Nm} \& 1800 \sim 2800 \mathrm{r} / \mathrm{min}$ \\
\hline Maximum injection pressure & $1600 \mathrm{bar}$ \\
\hline
\end{tabular}

The most common methods for achieving blended fuel have four kind:

-Alcohol-diesel fuel blends;

-Alcohol-diesel fuel emulsions;

-Dual injection;

-Alcohol fumigation. [1]

At present, the isopropanol application research on the engine is relatively few. This study use isopropanol in diesel engine is in the form of blends, investigates and compares the combustion and emission performance of diesel engine fueled with isopropanol-diesel blends.

\section{Test fuel and laboratory equipment}

Fuels used in test are conventional 0\# diesel, analysis-level isopropanol. On the basis of diesel oil, configure the volume content of 5\%, 10\%, 15\% and 20\% mixed fuel respectively. P5, P10, P15 and P20 means isopropanol-diesel fuel blends, D100 means pure diesel. 
Table 2. The main instruments of test equipment

\begin{tabular}{|c|c|}
\hline Device & Accuracy \\
\hline FC2210Z Intelligent fuel consumption instrument & $0.1 \%$ \\
\hline 2893A Vehicular combustion analyser & $\pm 0.5 \%$ \\
\hline 2614A Crankshaft signal photoelectric encoder & $\pm 0.002 \%$ \\
\hline GW250 Electric eddy current dynamometer & $\pm 1 \mathrm{r} / \mathrm{min}$ \\
\hline FC2000 Measurement and control system & $\pm 0.2-0.4 \% \mathrm{FS}$ \\
\hline Horiba MEXA-7100DEGR Gas emissions analyser & $\pm 1 \%$ \\
\hline
\end{tabular}

Experiments for pure diesel and isopropanol-diesel fuel blends were conducted in a 4 cylinder, 4 stroke, water-cooled, turbocharged, common-rail, direct injection diesel engine. The test speed of $2000 \mathrm{r} / \mathrm{min}$ and various loads $(90 \mathrm{~N} \cdot \mathrm{m}, 150 \mathrm{~N} \cdot \mathrm{m}, 210 \mathrm{~N} \cdot \mathrm{m}$ and $270 \mathrm{~N} \cdot \mathrm{m})$ were selected as the engine operating conditions. Main technical specifications of the engine are given in Table 1 . The main measure equipment and instruments are in Table 2. The physical and chemical characteristics of pure diesel and blended fuels are presented in Table 3.

Table 3. The Physical and chemical properties of pure diesel and blended fuels

\begin{tabular}{|c|c|c|c|c|c|}
\hline Property & D100 & P5 & P10 & P15 & P20 \\
\hline Volume fraction & 0 & 5 & 10 & 15 & 20 \\
\hline Density $\left(20^{\circ} \mathrm{C}\right) / \mathrm{g} \cdot \mathrm{ml}^{-1}$ & 0.842 & 0.839 & 0.836 & 0.833 & 0.830 \\
\hline Kinematic viscosity $\left(20^{\circ} \mathrm{C}\right) / \mathrm{mm}^{2} \mathrm{~s}^{-1}$ & 4.89 & 4.67 & 4.42 & 4.07 & 4.06 \\
\hline Low heating value $/ \mathrm{MJ} \cdot \mathrm{kg}^{-1}$ & 45.88 & 44.92 & 44.02 & 43.57 & 43.07 \\
\hline Surface tension $/ \mathrm{mN} \cdot \mathrm{m}^{-1}$ & 28.55 & 21.71 & 22.93 & 23.45 & 23.67 \\
\hline Flash point ${ }^{\circ} \mathrm{C}$ & 65 & 22 & 20 & 20 & 20 \\
\hline Volume fraction & 0 & 5 & 10 & 15 & 20 \\
\hline
\end{tabular}

\section{Results and discussion}

\subsection{Combustion characteristics}

Fig. 1 shows the heat release rate and in-cylinder pressure of various fuel blends. It can be seen that distinctive double peaks of in-cylinder pressure and heat release rate are found, the first peak corresponds to the pilot injection, and the second peak reflects the main injection. Characterization of the combustion in cylinder main stages of the second peak is the main object of study $[15,16]$. With the blending proportion of isopropanol increase, the first peak of mixed fuel of heat release rate and in-cylinder pressure decrease and lower than that of pure diesel, the second peak increase and higher than pure diesel. Due to the longer ignition delay of pilot injection raised by isopropanol addition, the mixing process of pilot injected fuel and air is enhanced, which could form over-lean regions where combustion does not happen, results in much lower pilot injection heat release rate and in-cylinder pressure [17]. Main injection phase as a result of the mixed fuel ignition period prolonged, the amount of combustible mixed gas increases, premixed combustion ratio increases, and isopropanol oxygen promote the process of combustion, the peaks of heat release rate and in-cylinder pressure increases. The interval of the first peak and the second gradually descend with the ratio of isopropanol ascend, this can be attributed to the low viscosity and density of isopropanol, the atomization quality improved, accelerate the speed of flame propagation, the combustion duration shortened, then promote the combustion. 


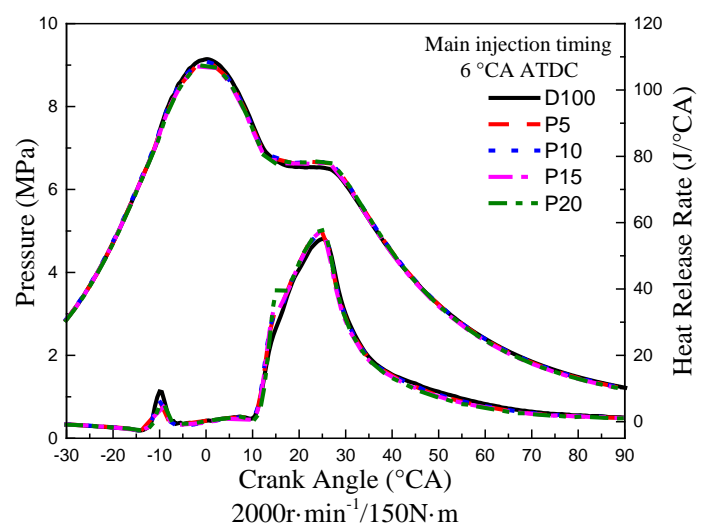

Figure 1. Heat release rate and in-cylinder pressure of various blends.

\subsection{Brake specific fuel consumption}

Fig. 2 indicates that the curve of brake specific fuel consumption of various blends under various conditions. It can be seen that brake specific fuel consumption decreases with the increase of the load. At the same load, the brake specific fuel consumption of five kind fuels increases with the increase of the mixing ratio of isopropanol. This is due to the temperature in the cylinder is getting higher and higher with the increase of the engine load, which provides good conditions for evaporation and atomization of fuel. Mixture of fuel and air more fully, so that the combustion is more sufficient, the fuel utilization rate increased significantly. The heat value of the fuel blends decreases with the increase of the proportion of isopropanol. In order to get the same output power, cycle fuel injection quantity increases. Thus the brake specific fuel consumption of the mixed fuel is increased. When the load is small, the heat loss is large, the combustion temperature of in-cylinder is lower, and the latent heat of vaporization of isopropanol reduces the combustion temperature further, the combustion quality becomes worse, so the change of the brake specific fuel consumption is obvious under the small load.

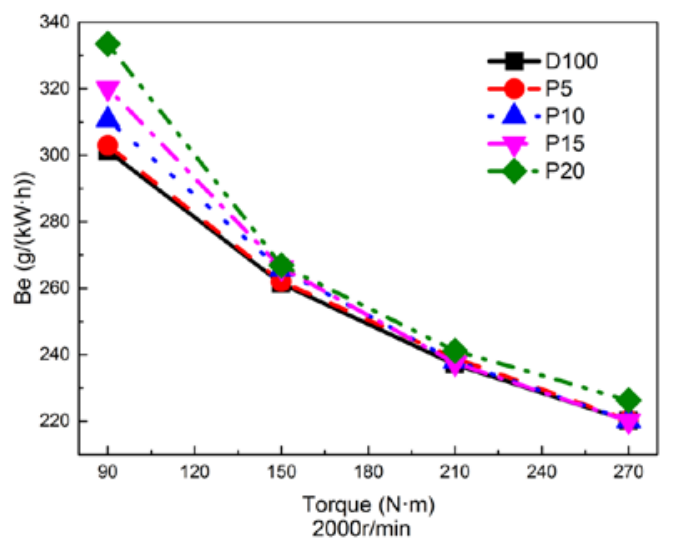

Figure 2. Brake specific fuel consumption of various blends under various loads.

\subsection{CO emission}

The Fig. 3 shows that the $\mathrm{CO}$ emission decreases with the increase of load. The $\mathrm{CO}$ is oxidized to $\mathrm{CO}_{2}$ rely on the presence of oxygen, suitable temperature and a longer period of time. With the increase of load, the combustion temperature increases, isopropanol containing oxygen promotes the combustion in cylinder, and the $\mathrm{CO}$ is oxidized further. Compared with the pure diesel fuel, the $\mathrm{CO}$ emission of 
the mixed fuels is reduced under the same operating condition except small load. The oxygen content of isopropanol increases the oxygen concentration in the combustion process, and makes the combustion of combustible mixture more complete. As the isopropanol mixing ratio increases, CO emission reduction ratio decreases. This may be attributed to synergistic effects of the latent heat of vaporization of isopropanol, and the oxygen content of isopropanol.

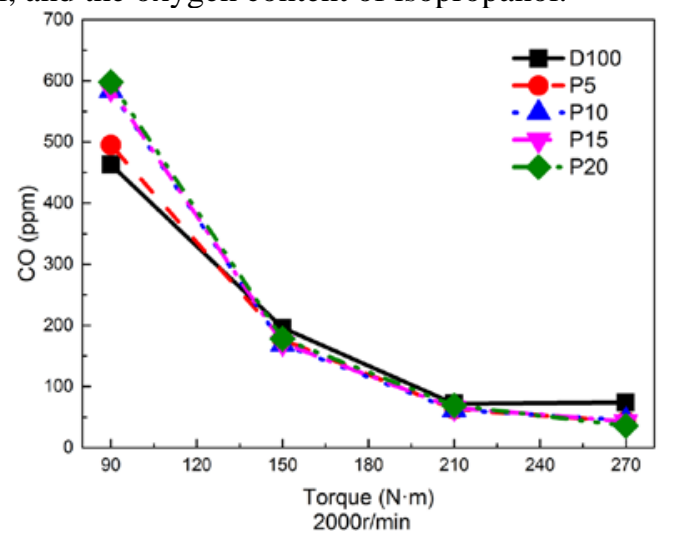

Figure 3. CO emissions of various blends under various loads.

\subsection{THC emission}

As can be seen from the Fig. 4, the THC emission decreases with the increase of load. The emission of THC is mainly caused by the unburned fuel and incomplete combustion. With the increase of load, the temperature and pressure of in-cylinder combustion increases, and the oxidation process of THC is accelerated. Under the same operating condition, the amount of air entering the cylinder is equal. The THC emission of the mixed fuel is slightly higher than that of pure diesel fuel, which is more obvious in the small load. This is due to the high latent heat of vaporization of isopropanol and lower cetane number lead to lower temperature in the cylinder under small load. The burning of ignition is poor, and there is even a partial quenching. In addition, the better volatility of isopropanol can expand the extinguishing fire area, especially the small load, and the effects of thin and cold shock is more obvious, which leads to the increase of THC emission. With isopropanol mixing ratio increases, THC emission increases. Generally speaking, the shorter the ignition delay period, the lower the THC emission is [18]. The cetane number of isopropanol is low, the ignition delay period is long, and the more hydrocarbon wall quenching. At the same time, isopropanol containing oxygen, reducing the area of over concentrated mixture in the cylinder, the combustion efficiency improved. And the THC emission is also decrease caused by the lack of oxygen in the combustion process $[9,18]$.

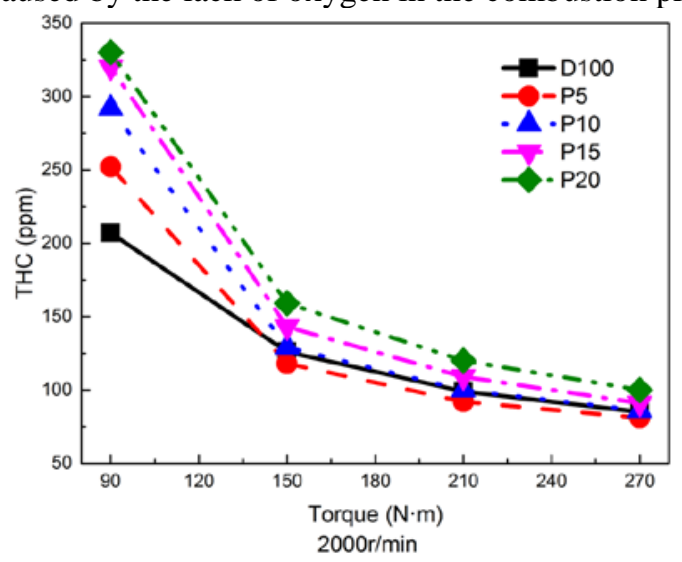

Figure 4. THC emissions of various blends under various loads. 


\subsection{NOx emission}

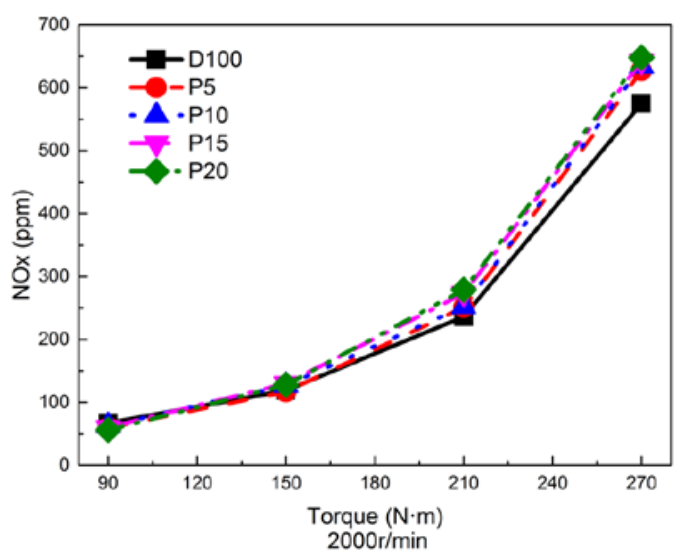

Figure 5. NOx emissions of various blends under various loads.

It is well known that the formation conditions of $\mathrm{NO} x$ are: high temperature, enough oxygen and sufficient reaction time. By the Fig. 5 we can see that the NOx emission increases with the increase of load. This is because the combustion temperature in cylinder increases with the increase of the load. At low load, the NOx decreases with the increase of isopropanol mixed ratio, while in the middle and high load is the opposite. This is because in the low load, the value of the latent heat of isopropanol is large, the heating value is low, and the temperature in the cylinder is lower. The higher the mixing ratio, the lower the temperature in the cylinder, which is not conducive to the formation of NOx. The influence of the latent heat of vaporization of isopropanol is decreased after the load increases. On the one hand, the oxygen content of isopropanol promotes the process of combustion, and the combustion temperature increases. At the same time, it generates the oxygen supply for NOx. In addition, the cetane number of mixed fuel is low, the ignition delay is prolonged. The viscosity and surface tension decreased to promote the atomization and evaporation of fuel, the combustion duration decreases. Combined with the above reasons, the NOx emission increases. With the increase of the proportion of the premixed combustion, the temperature of fast combustion period in the cylinder is increasing rapidly, and the combustion duration increases. This makes the three formation conditions of $\mathrm{NO} x$ are enhanced, so the NOx emission increases. And the NOx emission was increased by $0.54 \%, 0.84 \%$, $2.52 \%$ and $5.04 \%$ for the P5, P10, P15 and P20 respectively compared with pure diesel at operating condition of $2000 \mathrm{r} \cdot \mathrm{min}^{-1} / 150 \mathrm{~N} \cdot \mathrm{m}$.

\subsection{Smoke emission}

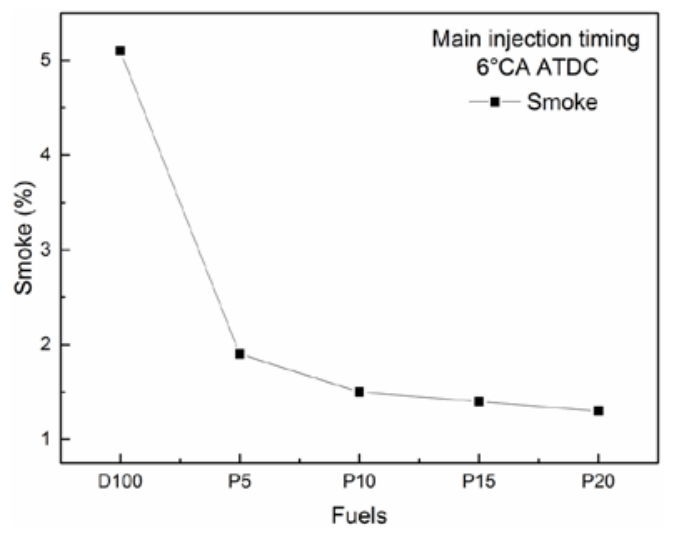

Figure 6. Smoke emissions of various blends under operating condition of $2000 \mathrm{r} \cdot \mathrm{min}^{-1} / 150 \mathrm{~N} \cdot \mathrm{m}$. 
It is pointed out that the smoke emission decreases with the increase of isopropanol proportion and sharply lower than pure diesel forms Fig. 6. Generally speaking, the formation of smoke is mainly caused by the cracking of high polymer hydrocarbon (especially the aromatic hydrocarbon) in high temperature and lack of oxygen in the concentrated mixture area of the combustion chamber [19]. The components of aromatic and naphthenic hydrocarbons in diesel provide a large number of complete aromatic and aromatic free radicals for the growth of smoke particles. It is helpful to the basic carbon particles in the formation of particles in the process of interaction with each other. Thus the formation of large particles containing more basic carbon particles and branched chain [20]. The content of aromatic hydrocarbon decreases after the diesel is blended with isopropanol. This "dilution effect" inhibits the formation of smoke emissions at the source. In addition, the boiling point and viscosity of isopropanol are lower, and the quality of fuel atomization is improved. The gas and fuel are mixing more fully, and the area of the over concentrated mixture is reduced. The latent heat of vaporization of isopropanol can reduce the combustion temperature of the cylinder, thereby reducing the thermal cracking reaction of fuel, and inhibiting the formation of smoke. Besides, the isopropanol is an oxygenated fuel, which promotes the combustion process, which is conducive to the further oxidation of smoke. Finally, the longer ignition delay period of fuel blends improves the degree of premixing of fuel and air, which is another reason for the decrease of the smoke emission. Therefore, under the same operating condition, the smoke emissions of the mixed fuel were significantly lower than that of the net diesel fuel. And the smoke density was decreased by $62.75 \%, 70.59 \%, 72.55 \%$ and $74.51 \%$ for the P5, P10, P15 and P20 respectively compared with pure diesel at the test operating condition.

\section{Conclusions}

In this work, isopropanol as additives to diesel were investigated in terms of performance and emission characteristics of a DI diesel engine running on various loads.

- As the blending proportion of isopropanol increased, the peaks of in-cylinder pressure and heat release rate of pilot injection were reduced, both peaks of main injection ascended. Brake specific fuel consumption increased and changes obviously under the small load conditions. The THC and NOx emissions increased except CO emissions, and smoke decreased significantly.

-Compared with the pure diesel, the isopropanol-diesel fuel blends could significantly reduce smoke emissions. And the smoke density was decreased by $62.75 \%, 70.59 \%, 72.55 \%$ and $74.51 \%$ for the P5, P10, P15 and P20 respectively compared with pure diesel at condition of $2000 \mathrm{r} \cdot \mathrm{min}^{-1} / 150 \mathrm{~N} \cdot \mathrm{m}$. While NOx emission was increased by $0.54 \%, 0.84 \%, 2.52 \%$ and $5.04 \%$ for the P5, P10, P15 and P20 respectively. Comprehensive consideration of engine combustion, economy and emission performance, recommended optimal blending proportion of isopropanol is $10 \%$.

\section{Acknowledgements}

The work was supported by International cooperation project of Henan province (144300510039).

\section{References}

1. Avinash Kumar Agarwal, Atul Dhar, et al. Effect of fuel injection pressure and injection timing of Karanja biodiesel blends on fuel spray, engine performance, emissions and combustion characteristics[J]. Energy Conversion and Management 91, 302-314 (2015) .

2. Satish Kumar, Jae Hyun Cho. Advances in diesel-alcohol blends and their effects on the performance and emissions of diesel engines [J]. Renewable and Sustainable Energy Reviews 22, 46-72(2013).

3. D.C. Rakopoulos, C.D. Rakopoulos, et al. Effects of butanol-diesel fuel blends on the performance and emissions of a high-speed DI diesel engine [J]. Energy Conversion and Management 51, 1989-1997 (2010). 
4. Jiang Deming. Advanced Internal Combustion Engine Fundamentals [M]. Xi'an: Xi'an jiaotong university press, (2007).

5. Teresa M. Mata, Adélio M. Mendes, et al. Sustainability and economic evaluation of microalgae grown in brewery wastewater [J]. Bioresource Technology 168, 151-158(2014).

6. M. Mani, G. Nagarajan. Influence of injection timing on performance, emission and combustion characteristics of a DI diesel engine running on waste plastic oil [J]. Energy 34, 1617-1623(2009).

7. Wagner TO, Gray DS, Zarah BY, Kozinski AA. Practicality of alcohols as motor fuel[C]. SAE paper no. 790429; (1979).

8. Bin $\mathrm{Xu}$, Yongfang Pan, et al. Combustion Characteristics of a Diesel Engine Fueled with Methanol-diesel Blends [J]. Journal of Agricultural Mechanization Research 34(2) (2012).

9. Adelman H. Alcohols in diesel engine[C]. SAE paper no. 790956, (1979).

10. Cenk Sayın. Engine performance and exhaust gas emissions of methanol and ethanol-diesel blends [J]. Fuel, V89, I11, P3410-3415, (2010).

11. Claudia Esarte, María Abián, et al. Gas and soot products formed in the pyrolysis of acetylene mixed with methanol, ethanol, isopropanol or n-butanol[J]. Energy 43, 37-46(2012).

12. Lv Xingcai, JI Li bin, et al. Parametric Study on Emissions and Heat Release Analysis of Combustion of HCCI Engines Fueled with Isopropanol/n-Heptane Blend Fuels [J]. Journal of Combustion Science and Technology, 13(3)(2007).

13. Hotzapple M, Davidson RR, et al. Biomass conversion to mixed alcohol fuels using the MixAlco process [J]. Appl. Biochemist Biotechnology. 79(60): 9-31(1999).

14. Myburgh IS. Performance and durability testing of a diesel engine fuelled with a propanolplus/diesel blend[C]. SAE Paper 95(10): 11-21(1986).

15. Donghui Qi, Michael Leick, et al. Effect of EGR and injection timing on combustion and emission characteristics of split injection strategy DI-diesel engine fueled with biodiesel [J]. Fuel. 90, 1884-1891 (2011) .

16. Mei Deqing, Ren Hua, Jiang Shiyang, et al. Effects of multiple injections strategy on combustion process of mixed fuels with dimethyl carbonate and diesel [J]. Transactions of the Chinese Society of Agricultural Engineering (Transactions of the CSAE), 30(8): 74-80, (2014).

17. Mingfa Yao, Hu Wang, et al. Experimental study of n-butanol additive and multi-injection on HD diesel engine performance and emissions [J]. Fuel 89, 2191-2201(2010).

18. Ma Zhihao, Wang Xin, et al. Effects of fuel injection timing on economy and emissions of diesel engine fueled with diesel/biodiesel blends [J]. Transactions of the CSAE, 27(2): 151-155, (2011).

19. John Benjamin Heywood. Internal Combustion Engine Fundamentals [M]. New York: McGrawHill Book Company, (1988).

20. Danna A, Ciajolo A, et al. Effect of fuel/air ratio and aromaticity on the molecular weight distribution of soot in premixed n-heptane flames[C]. Proc. Combust. Inst., 32(1): 803-810(2009). 